I Universidade de São Paulo (USP), Escola de Artes, Ciências

e Humanidade (Each), São Paulo, SP, Brasil

machado@usp.br

https://orcid.org/oooo-0002-I23I-6665

I I Universidade Federal de São Paulo (Unifesp), Departamento

Jorge Machado'

de Medicina Preventiva, São Paulo, SP, Brasil

richard.miskolci@unifesp.br

Richard Miskolci"

https://orcid.org/oooo-0002-6405-559I

\title{
DAS JORNADAS DE JUNHO À CRUZADA MORAL: O PAPEL DAS REDES SOCIAIS NA POLARIZAÇÃO POLÍTICA BRASILEIRA
}

Qual foi o papel desempenhado pelas redes na criação das polarizações políticas que marcam a vida política brasileira desde as Jornadas de Junho? De que modo elas se relacionam com a cruzada moral que vivemos nesses dias? Neste artigo, buscamos compreender o papel político das redes sociais no acirramento de disputas políticas e morais no Brasil desde 20I3. A crise política parece ter disparado elementos que estavam latentes, mas que ainda não encontravam terreno propício à sua expressão. Embora o êxito político de grupos com agenda moral conservadora tenha raízes nas contradições históricas do país, buscamos neste texto compreender como as redes sociais acentuaram esse processo. Analisamos a disseminação das redes sociais enquanto uma tecnologia catalisadora de um processo histórico.

$\mathrm{O}$ artigo se insere na linhagem analítica da moldagem social da tecnologia (Williams, 20I5), portanto busca manter uma perspectiva crítica aos determinismos tecnológicos: tanto os que atribuem à tecnologia todos os males contemporâneos quanto os que se assentam em expectativas de soluções técnicas para questões sociais. Assim, consideramos fundamental evitar a mera culpabilização de plataformas de rede social ou alguma de suas funcionalidades pelos resultados do que identificamos sociologicamente como uma disputa cognitiva nas redes visando projetar para o indivíduo uma experiência de realidade direcionada e motivada por objetivos econômicos e políticos subjacentes à própria estrutura social. 
Compreender o papel das redes sociais no contexto político brasileiro contemporâneo exige associar diferentes perspectivas analíticas. Neste artigo, articulamos duas pesquisas: uma sobre o controle econômico das redes e outra envolvendo seu uso na disseminação de pauta moralizante na esfera da sexualidade e do gênero. A partir da revisão da bibliografia disponível sobre o uso das redes e da observação sistemática da aliança de grupos políticos de extrema- direita que se forjou a partir de 2013, construímos a base empírica de nossa reflexão. A observação dos grupos se deu de duas formas: qualitativamente por meio da seleção, acompanhamento e análise dos perfis e postagens daqueles que se aliaram desde 20 I 3 em torno de uma agenda política comum; e, de modo complementar, em termos quantitativos, também pelos dados disponibilizados nos relatórios semanais do Manchetômetro ${ }^{\mathrm{I}}$ sobre os posts mais compartilhados nas redes sociais.

As transformações proporcionadas pela internet já foram avaliadas sob perspectivas distintas, como "capitalismo cognitivo" (Boutang, 2005; Hardt \& Negri, 2004); “economia da atenção" (Goldhaber, I997; Davenport \& Beck, 200I), que visa manter o usuário conectado o maior tempo possível, tanto para coletar dados como para vender anúncios; "capitalismo da vigilância” (Foster \& McChesney, 20I4; Zuboff, 20I5), no qual o comportamento do usuário na rede, assim como dados ambientais coletados pelos sensores dos smartphones e geolocalização, alimenta os big data vendidos a terceiros com propósitos diversos - incluído o de manipulação política; outros chamam a atenção sobre processos emocionais-cognitivos que o uso da rede tem causado nos sujeitos - segundo Sherry Turkle (20I I) ela nos conecta na mesma proporção em que nos afasta, criando uma nova forma de solidão. O "efeito bolha" das redes sociais (Pariser, 20 I I), em que as visões de mundo acabam sendo reforçadas entre grupos específicos, também tem sido foco de preocupação pelo fato de formar consensos polarizados. Mais recentemente, análises chamam a atenção para a coleta massiva de dados comportamentais, a aplicação de aprendizado de máquina, inteligência artificial e ciência de dados para aprimoramento algorítmico contínuo com fins de perfilamento e predição comportamental dos usuários² (Zuboff, 20ı6; Rouvroy \& Berns, 20I5).

É certo que todas essas perspectivas nos permitem formar um quadro maior do poder invisível das redes - controladas por poucas empresas - sobre bilhões de pessoas, cujo prospecto de lucros se baseia na vigilância e venda de dados pessoais com propósitos diversos. Atualmente, poucas empresas concentram o poder de coletar o máximo de informações sobre os indivíduos antes fragmentadas e distribuídas na internet - de modo a fazer predições comportamentais e influenciar a formação de opiniões, valores e processos de tomada de decisão.

Nesse mercado de dados, o que interessa não é um indivíduo "fragmentado", anônimo ou escondido sob pseudônimos (Ramos, 20I5), mas sim um 
indivíduo unificado, reconhecível, coerente, monitorável e previsível. Quanto maior a precisão, mais se pode extrair "valor de mercado" do cidadão-consumidor conectado. Não foi por acaso que nos últimos anos o centro da economia capitalista global passou a ser o mercado de informação, expresso pelas primeiras cinco posições das empresas de tecnologia como as mais valiosas do mundo 3 (Parra et al., 2018: 66).

Os interesses econômicos aliados ao grande volume de dados não deixariam de se traduzir em interesses políticos. Compreender as lógicas de uso das redes sociais envolve também identificar sua maneira de se associar às mídias de massa prévias e o modo como tais interesses se relacionam. Ainda é preciso, portanto, analisar melhor tal convergência tecnológico-midiático-política como mais do que mera incorporação e disseminação dos conteúdos das antigas mídias pelas novas: a difusão - de forma nunca antes vista - de sua cultura da popularidade. As relações por meio das redes sociais atraem e cativam ao inserir seus usuários em uma economia midiática do reconhecimento regida pela busca de atenção.

Como meio escasso, a popularidade nesses ambientes é disputada moldando interações competitivas que tendem a premiar os mais bem sucedidos em angariar apoio a suas postagens, as quais agregam seguidores ao usuário, conferindo-lhe o grau máximo de sucesso online: a condição de influenciador digital, "protagonismo" ou apenas satisfação de tornar-se o centro momentâneo das atenções. Nesse meio, explicações simplistas com apelos morais encontram potencial de difusão. De acordo com Frank Pasquale (20I7: I8), a seleção de conteúdo a partir de sua "viralização" tende a favorecer uma diversidade pobre de temáticas em vez de um pluralismo positivo e democratizante. Segundo o autor, a relevância dada a esse conteúdo com base em métricas de atenção popular "verificada pelo número de visualizações, curtidas e compartilhamentos contribui para a disseminação de conteúdos independentemente de sua veracidade, integridade ou qualidade".

Interesses econômicos, políticos e também consequências inesperadas do uso das redes sociais são exploradas a seguir. Iniciamos com uma breve reconstituição histórica dos usos da internet por grupos políticos de direita e esquerda, digressão necessária para inserir as Jornadas de Junho de 2013 no Brasil num contexto mais amplo. A partir disso traçamos uma timeline, com os eventos históricos significativos. A seguir apresentamos elementos empíricos e analíticos para apoiar conclusões sobre o papel das redes sociais na consolidação de uma gramática moral em suas disputas políticas.

\section{OS USOS DA INTERNET POR GRUPOS POLÍTICOS DE DIREITA E ESOUERDA}

As raízes históricas do pensamento e da mobilização na internet desde seu surgimento como rede comercial na década de I990 nos ajudam a compreender os grupos mais extremos do espectro político à esquerda e à direita (Ma- 
chado, 2007). Tal empreitada se justifica pela clara relação entre as pautas conservadoras de grupos como Movimento Brasil Livre (MBL), Endireita Brasil, Instituto Millenium, Vem pra Rua e Revoltados Online com ideólogos que há cerca de duas décadas propagavam seu ideário por meio das TICs (tecnologias de informação e comunicação).

Podemos reconstruir, na história da internet, uma cronologia desse pensamento que levou à polarização atual. Os grupos de esquerda foram os primeiros que conseguiram fazer uso da rede com maior impacto na opinião pública, como atesta a mobilização internacional em torno do movimento zapatista (I998), em que a figura do herói anônimo mascarado chamado de subcomandante Marcos se disseminou mundialmente apoiada em grupos de jovens de esquerda (Ortiz, 2005). A revolução popular surgida na província mexicana de Chiapas alcançava a mídia pela mobilização de hackers, movimentos sociais, partidos de esquerda e grupos autonomistas. Eles consideravam Chiapas uma nova expressão de uma organização social de base agrária, indígena, que dava nova cara a um socialismo humano no contexto da então chamada Nova Ordem Mundial. ${ }^{4}$

As primeiras manifestações antiglobalização em Seattle (I999) marcaram também o surgimento de uma mídia independente, dentro da qual se destacava a Indymedia ou Independent Media Center (IMC), que formava uma rede alternativa de jornalistas - espécie de precursora da Mídia Ninja (Pickard, 2006). Essa denominação era também alusiva a um movimento musical jovem de finais do século XX que se distinguia do mainstream. Os protestos durante a cúpula da Organização Mundial do Comércio (OMC), em Seattle, resultaram em batalhas nas ruas com a polícia, que impediam o deslocamento na cidade dos delegados e da imprensa. As imagens que chegavam no noticiário da grande mídia eram aquelas disponibilizadas nas redes pelos jornalistas independentes articulados pela Indymedia. Com isso, o mundo inteiro conheceria a Indymedia, que até então não passava de uma rede global alternativa articulada pela internet e apoiada no voluntarismo.

Os baixos custos operacionais e de comunicação da internet beneficiaram tanto a rede de jornalistas independentes como coletivos de ativistas do mundo inteiro. Naquela época, a internet era praticamente estática - ao contrário da interativa Web 2.0, pois não havia Facebook nem Twitter. E o Google era apenas um mecanismo de busca entre outros. A Indymedia emergiu como centro da mídia alternativa que fazia frente à tradicional. Seus textos não eram escritos apenas por jornalistas, mas também por qualquer ativista, mesmo sob anonimato, já que sua publicação não passava por nenhuma forma de moderação; qualquer um podia usar o site - editado em várias línguas - para difundir notícias, ideias, eventos. Dessa forma, a plataforma permitia que vídeos e fotos pudessem ser livremente postados, com proteção de sigilo da fonte - uma vez que o servidor era controlado por ativistas e tinha seus conteúdos encrip- 
tados. Naqueles tempos, sem redes sociais comerciais e com os blogs ainda em sua infância, uma rede global alternativa para difundir notícias e mobilização parecia algo revolucionário para fazer frente à grande mídia.

A Indymedia passou gradualmente a ser alvo de ataques de grupos de direita no mundo todo. No Brasil, na segunda metade dos anos I990, Olavo de Carvalho já despontava com seu site, em que publicava textos defendendo teses conservadoras, nas quais articulava a obra de pensadores de direita visando ressignificá-los para cativar o público brasileiro. Com isso, Carvalho dava um verniz de suposto fundo filosófico a suas ideias políticas, atraindo um grande número de seguidores, em especial jovens brancos de classe média e alta.

Olavo de Carvalho - inspirador das principais lideranças dos grupos de direita na rede, como MBL e Vem Pra Rua, e guru ideológico do governo Bolsonaro - foi um dos pioneiros do ativismo de direita na internet, com suas críticas ácidas e sarcásticas a grupos e partidos progressistas. Isso o tornou alvo de ativistas de esquerda. A Indymedia servia de palco frequente para os ataques e piadas a ele dirigidos. Como resposta, Carvalho criou em 2002 sua própria rede de informação alternativa: a Mídia sem Máscara (MSM). Visando fazer frente aos meios de comunicação de esquerda, a MSM engajava uma rede de colaboradores para apresentar suas visões dos fatos a partir de uma perspectiva de direita (Patschiki, 20I2). O website viria a se tornar epicentro para a tradução de análises políticas de pensadores conservadores da América Latina, da Europa e dos Estados Unidos. Além disso, abordaria sob uma perspectiva moralista temas como homossexualidade, gênero, direito ao uso de armas, defesa da propriedade privada e "esquerdismo". A MSM servia de ponta de lança para ataques à esquerda e de difusão da ideologia da direita e, em especial, dos textos de seu próprio fundador.

Tanto a MSM como a Indymedia viriam a perder muito de sua força com a migração gradual do público para as redes sociais. Tal fenômeno não seria possível sem a explosão do número de pessoas com acesso à internet e, em especial, sua entrada em plataformas como o Facebook, com funcionalidades que prendiam muito mais a atenção dos usuários. Segundo dados da International Telecommunication Union (ITU), agência especializada das Nações Unidas sobre TICs, é possível reconhecer que o número de usuários da internet aumentou associado à popularização do acesso por smartphones, portanto na década de 20 I0. ${ }^{5} \mathrm{Na}$ visão de autores como Van Dijck (20I6), a explosão do número de usuários da internet e a chegada dos serviços de redes sociais comerciais modificaram a rede de um espaço de conexões mais abertas para um ecossistema reduzido de plataformas que concentra a maior parte do tráfego online.

O radicalismo à esquerda e à direita na internet não foram, portanto, uma novidade da década de 20ıo, pois já se desenvolvia em um meio ainda menos consolidado comercialmente e com maior espaço para conexões menos 
automáticas como as de nossa era regida pelas plataformas de rede social de fundo algorítmico. Naquela época, havia uma profusão de perfis online, o uso de pseudônimos era recorrente, e o ambiente aparentemente anárquico contribuía para dificultar a formação de polarizações visíveis e massivas.

Com a emergência das redes sociais, os usos políticos da Web 2.0 originariam grandes manifestações como os da chamada Primavera Árabe (20I0), Occupy Wall Street (20I I) e Indignados (20I I). Tais mobilizações apoiavam-se na facilidade de compartilhar conteúdos, na popularidade de perfis pessoais e, sobretudo, no poder dos algoritmos em atrair a atenção, agregar apoio às causas, induzindo à ação política. No Brasil, embora tenham surgido fenômenos como "rolezinhos" - jovens da periferia que marcavam grandes encontros em shopping centers - ou as marchas da maconha e das vadias, ambos organizados pelo Facebook, foi só em 20I3, com as chamadas Jornadas de Junho, que o uso político das redes sociais comerciais alcançou impacto em toda a sociedade.

Desde então, linhas de força políticas indissociáveis de seu caráter tecnológico-comunicacional marcaram a inflexão para uma nova gramática de disputas, mais conflitiva e moralista. As redes sociais e demais plataformas comerciais online têm gerado não apenas os já estudados fenômenos das bolhas de opinião ou a disseminação de fake news, mas algo mais radical e preocupante enquanto elemento central da ação política: a privatização da política e sua inserção em uma gramática moral. A seguir, trazemos alguns elementos para discutir como ao invés de o pessoal ter-se alçado ao político, como na clássica asserção feminista da década de I960, vemos - nas redes sociais contemporâneas - o político ser reduzido ao pessoal. Tal privatização da política gera ação coletiva frequentemente anti-institucional com potencial de desestabilizar contextos democráticos.

Quadro Evolução da internet e polarização política 


\begin{tabular}{|c|c|}
\hline 1995 & Internet comercial \\
\hline 1997 & Olavo de Carvalho (site) \\
\hline 1998 & Movimento zapatista na internet \\
\hline 1999 & Indymidia // Surgimento dos bloggers \\
\hline 2002 & Midia Sem Máscara \\
\hline 2006 & Surgimento da Web 2.0 \\
\hline 2007 & Surgimento do Facebook \\
\hline 2010 & Primavera Árabe // Botão de curtir Facebook // Declínio dos blogs (cf. Google trends) \\
\hline $201 \mathrm{I}$ & $\begin{array}{l}\text { Movimentos Indignados (Espanha) e Occupy Wall Street (EUA) // Reconhecimento } \\
\text { das uniões homossexuais pelo STF no Brasil/ Bolsonaro articula movimento } \\
\text { contra a distribuição de material anti-homofobia (Kit Gay) }\end{array}$ \\
\hline 2012 & Consolidação da Web 2.0 // Oligopolização da internet por cinco empresas \\
\hline 2013 & $\begin{array}{l}\text { Jornadas de Junho // i8 anos da web // revelações de Snowden // STF iguala } \\
\text { uniões homossexuais ao casamento // Comissão de Direitos Humanos do } \\
\text { Congresso fica sob controle da bancada evangélica }\end{array}$ \\
\hline 2014 & $\begin{array}{l}\text { Protestos contra Copa do Mundo //Acesso à internet passa a ser principalmente } \\
\text { por smartphones // Votação do Plano Nacional de Educação }\end{array}$ \\
\hline 2015 & $\begin{array}{l}\text { Protestos por impeachment de Dilma // Surgem MBL e Vem Pra Rua // Campanha } \\
\text { contra ideologia de gênero nos planos estaduais e municipais de educação }\end{array}$ \\
\hline 2016 & $\begin{array}{l}\text { Impeachment de Dilma//Olimpíadas//Início de Operações da PF mirando } \\
\text { universidades públicas }\end{array}$ \\
\hline 2017 & $\begin{array}{l}\text { Facebook supera 2bi usuários//Protestos contra e a favor da prisão de } \\
\text { Lula//Cruzadas morais contra artistas e intelectuais//Suicídio do reitor } \\
\text { da UFSC//Perseguição a Judith Butler }\end{array}$ \\
\hline 2018 & $\begin{array}{l}\text { Prisão de Lula//Ações judiciais e da justiça eleitoral nas universidades// } \\
\text { Eleição de Bolsonaro e de outros políticos da extrema-direita }\end{array}$ \\
\hline 2019 & $\begin{array}{l}\text { Denúncia do uso do WhatsApp por financiamento ilegal//Ataques à im- } \\
\text { prensa//Corte de verba das universidades e órgãos de financiamento à pes- } \\
\text { quisa//Fim das políticas voltadas para as minorias }\end{array}$ \\
\hline
\end{tabular}




\section{A PRIVATIZAÇÃo dA POLÍTICA E A EMERGÊNCIA dE NOVAS CRUZADAS MORAIS}

A história do uso das mídias sociais com propósitos democráticos e de organização de movimentos sociais se deu paralelamente à criação de outro uso, mais afeito aos grupos autoritários, que buscavam defender o status quo ou propagar o pensamento conservador. Na década de 20 Io, há um barateamento e consequente popularização dos smartphones, o que explica a já mencionada explosão do número de usuários da internet que, no Brasil, segundo dados da Pesquisa Nacional por Amostra de Domicílios do IBGE, tornou o acesso via celular o preponderante a partir de $2014 .^{6}$

Segundo Van Dijck (20I6), é também nesta década que a rede passa a funcionar como um ecossistema concentrado de plataformas, que substituíram de vez a conexão relativamente independente do usuário por uma sociabilidade induzida por algoritmos mediante o processamento de seus dados e "preferências" pessoais. Os algoritmos das plataformas de rede social "guiam" os usuários sugerindo-lhes amigos, expondo-os a determinados conteúdos - e não a outros -, assim como induzindo-os a se manifestar sobre certos temas. Algoritmos funcionam como regras de racionalidade que substituem os julgamentos autocríticos da razão. São as empresas donas das plataformas que definem, segundo seus interesses, o funcionamento dos algoritmos. Não havendo forma de os regular - fazem parte do chamado segredo de negócio -, caracterizam-se por ser opacos, enviesados, obscuros e inescrutáveis (O'Reilly 20I3). Segundo Introna e Nissenbaum (2000), ainda podem ser discriminatórios e, na visão de Gillespie (2013), servir à vigilância.

É nesse contexto que os recém-chegados ao mundo digital foram acolhidos em serviços comerciais de rede social que se tornaram também portais de entrada à internet delimitando seus usos. A rede, portanto, deixou de ser a aparente janela para o mundo que conheceram seus primeiros (e privilegiados) usuários das classes-médias profissionais do Ocidente para se tornar predominantemente um ambiente comercial, controlado e vigiado por corporações. Assim, chegamos a um contexto em que um punhado de plataformas como Facebook, YouTube, Instagram, Twitter e Google promovem uma sociabilidade induzida por algoritmos que visam reter o máximo da atenção diária de usuários em todo mundo. A chamada Web 2.0 - comercialmente anunciada como uma web mais interativa e social - acentuou gradualmente o lado mais comercial da rede a partir da segunda metade da década de 2000 em um processo de convergência com a grande indústria do entretenimento. Controlada por corporações do Vale do Silício, sua hegemonia é indissociável da quase ubiquidade dos serviços comerciais de rede social, dos quais o Facebook é o mais popular e poderoso.

Criado em 2007, o Facebook alcançou, dez anos depois, dois bilhões de usuários no mundo todo. É uma plataforma privada em que os usuários são 
"criadores", ou ao menos compartilhadores, de conteúdo. Desde 20Io, com a introdução do botão "curtir" (like em sua versão original) e do Open Graph, a rede ganhou suas características mais importantes: I. o botão "curtir" introduziu a lógica da popularidade e da competição por atenção na rede social intensificando as conexões e 2. o Open Graph permitiu que sítios externos usassem as informações que a plataforma colhe de seus usuários criando "experiências personalizadas" em suas próprias páginas (cf. Van Dijck, 2016: 82). Criavam-se, assim, as condições para que - poucos anos depois - começassem a se tornar perceptíveis os aspectos conflitivos advindos do uso da plataforma.

O próprio acesso dos usuários a uma rede social como o Facebook ocorre por meio do uso individualizado de dispositivos. Uma vez na plataforma, algoritmos influenciam as interações entre os usuários, sem que eles conheçam seu funcionamento. Tal fenômeno constitui um verdadeiro "inconsciente tecnológico" (Thrift, 2004; Burrows \& Beer, 2013) que tem papel decisivo nas relações forjadas por meio desses equipamentos e plataformas. Seu aspecto sombrio não se resume ao controle e/ou à vigilância das grandes corporações, mas também às consequências subjetivas do uso contínuo dessas tecnologias.

O uso das TICs incentiva a reiteração de convicções que induzem à polarização de perspectiva, além da consequente modulação das relações sociais que alguns, como Sherry Turkle (20I I), veem como empobrecendo os laços sociais e que, em nossa análise, buscamos compreender em suas consequências políticas. A modulação das relações sociais envolve tanto as funcionalidades introduzidas pelas novas tecnologias que permitem a seleção de contatos, mais impessoalidade nas interações e até o bloqueio de alguns quanto à preferência crescente dos usuários por mensagens editadas em relação às interações abertas ao acaso e às reações inesperadas de um interlocutor, como nos telefonemas. Tal "costumização" da comunicação permite editar a visão da realidade do sujeito e até mesmo privatizar o espaço público quando, por exemplo, fala em público ao telefone ou grava mensagens de voz na rua como se estivesse sozinho em casa.

Cabe acrescentar que, para reunir o máximo de informações e perfilar seu público, empresas como o Facebook e o Google desenvolveram formas de centralizar a informação dos indivíduos, incentivando o uso da plataforma para "logar" em outros sites. Isso foi gerando uma unificação das identidades/ perfis online. Identidade é aqui compreendida como o expresso por um perfil na comunicação por plataformas online. Antes da oligopolização da internet, cada sujeito podia ter perfis adaptados segundo cada plataforma e/ou contexto, mas os interesses de controle de dados e exploração comercial levaram à unificação atual.

Uma forma de entender as consequências disso é lembrar que antes as pessoas se comunicavam de formas diferentes com familiares, amigos, namorada/o, colegas de trabalho, parentes mais distantes e mesmo com estra- 
nhos. Em plataformas como o Facebook, comunicam-se com todos da mesma forma. ${ }^{9}$ Isso potencializa o chamado "colapso contextual" (Marwick \& Boyd, 20I0). A contextualização era importante, pois possibilitava ao usuário direcionar a mensagem ao interlocutor adequado, mantendo assim, de certa forma, diversas "identidades" que permitiam modular a comunicação. Os contextos se colapsam quando, ao se comunicar com todos, comunica-se de forma igual àquela usada para se comunicar individualmente.

O uso de plataformas de comunicação online introduziu o usuário em um contexto altamente individualizado em que as relações mesmo sendo diretas ganham impessoalidade. Comportamentos e opiniões que não seriam tolerados em relações face a face passam a se expressar gerando apoios e rejeições para se tornar consensos polarizados. No que se refere à plataforma em questão, seu algoritmo que cria relações, indica "amigos" e oferece "experiências personalizadas", acrescenta condições para que o usuário passe a viver dentro de uma "bolha de opinião" que reforça suas convicções e amplia suas divergências em relação a outras não apenas no que se refere a temas macropolíticos, mas sobretudo comportamentais.

Acessadas individualmente - e por meio de um perfil que cria uma espécie de self online - as redes sociais operam em uma lógica de competição em que pautas coletivas ganham mais apoio quanto mais se traduzem em um repertório moral. A construção de um perfil online envolve a incorporação de expedientes midiático-comerciais para expressar uma suposta identidade materializável em um estilo de vida que é, também, inseparável de valores. Parte da "mágica" das redes sociais - sua eficácia comercial - está em criar a ilusão de alçar qualquer usuário à esfera do sucesso e do prestígio, mas também de premiar o senso comum como eixo de afinidade e construção de redes e, mesmo, de ação coletiva.

Hoje poucos questionam o poder de mobilização das redes sociais, mobilização compreendida no sentido de que efetivamente quem usa uma plataforma de socialização tende a se sensibilizar por causas de algum tipo a ponto de compartilhar conteúdos sobre elas e até sair às ruas em protesto. Tais causas podem ser coletivas, como a luta contra a corrupção, mas nas redes elas tendem a serem lidas em chave personalística. Isso deu margem para o sensacionalismo e a emergência das fake news ${ }^{10}$ como estratégia de formação de opinião e mobilização. As plataformas tendem a incentivar um tipo de associação política que frequentemente induz à vigilância alheia criando ondas de denúncias, perseguições e até linchamentos online. Sobretudo, uma ação coletiva fundada em valores individualistas e sob uma perspectiva privatizada da política que tende a colocar instituições sob suspeita e, eventualmente, voltar-se contra elas.

Os acontecimentos históricos tendem a corroborar a hipótese de que, inicialmente, o uso da internet por vertentes políticas radicais foi potenciali- 
zado no contexto inaugurado pelos serviços comerciais de rede social baseados na conectividade. O fato de que eventos como Occupy, Primavera Árabe e Indignados foram organizados, ao menos em parte, por meio dessas plataformas levou a reforçar as expectativas de que as TICs teriam um efeito de reforço e ampliação de forças políticas transformadoras até que, em 20I3, esse tipo de mobilização social chegou ao Brasil.

As chamadas Jornadas de Junho começaram com protestos organizados pelo Movimento Passe Livre (MPL) - frente de muitos movimentos sem uma linha política definida (Pomar, 2013) - contra o aumento da tarifa de ônibus na cidade de São Paulo. Um dos slogans das Jornadas era "não me representa", o que simultaneamente expressava uma crença na ação direta (via internet e nas ruas) e desacreditava a base da democracia representativa, os partidos e os políticos. ${ }^{\text {II }}$ As manifestações organizadas pelo MPL, com a pauta unificada contra o aumento do transporte público de São Paulo em "2o centavos", atraíram um grande número de jovens, muitos dos quais saíam às ruas para manifestar-se politicamente pela primeira vez. Logo, muitos ativistas e grupos de orientação ideológica distintas e até divergentes foram se juntando, tentando colar sua própria pauta e imprimir uma identidade às manifestações.

É nesse momento que começam as manifestações contra o governo do Partido dos Trabalhadores (PT) e o clamor "Fora Dilma". Grupos ligados a partidos políticos passaram a ser hostilizados, e as cores verde e amarela da bandeira - historicamente usadas pela direita - tornaram-se mais presentes nos protestos. Ao reconhecer a infiltração de grupos conservadores nas manifestações e temendo que o movimento tomasse um sentido não desejado, o MPL decidiu parar com os protestos. ${ }^{\mathrm{I2}}$ No entanto, eles continuaram, desta vez sob a batuta de grupos e lideranças mais à direita no espectro político, com o apoio de artistas que deram maior dimensão midiática a esse movimento. Frases de efeito das jornadas foram "emprestadas" à publicidade, como o slogan "Vem pra rua, vem" retirado de uma propaganda de automóvel.

Os protestos de 2013 podem ser tomados como o ponto de inflexão histórico a partir do qual disputas políticas passaram a se dar dentro de uma retórica antipartidária, que aos poucos foi se aproximando de uma gramática moral que alimentaria uma cruzada "saneadora" contra a corrupção. Uma rede de websites de perfil político conservador emergiu angariando um número considerável de seguidores nas redes sociais que repercutiam suas notícias - incluído o que hoje é chamado de fake news - levando-os às ruas - o que até então era muito mais frequente por parte de grupos progressistas, como demonstrado, por exemplo, pela Marcha da Maconha, pela Marcha das Vadias, pelo Movimento do Passe Livre etc.

A partir de 2013, "político" deixou de ser substantivo e passou a ser um adjetivo usado negativamente para desqualificar pessoas, ideias, análises. Paralelamente a isso, foi emergindo um vocabulário que rechaça a ideia de lide- 
rança, prioriza a ação direta (até violenta) em detrimento das formas de diálogo e da negociação política. Observa-se nesse ponto, a extrapolação para a vida cotidiana offline de um acirramento das posições que parece espelhar o fenômeno das bolhas de opinião das redes sociais. Desde então, tais bolhas e as manifestações divergentes nas ruas passaram a se retroalimentar e se digladiar.

Foi na esteira do legado das Jornadas de Junho de 2013, nos primeiros meses de 20I5, que as manifestações e protestos contra o governo Dilma Rousseff começaram a se apresentar como supostamente apartidárias e até como "não políticas", e aos jovens se juntaram outros segmentos etários. Gradualmente, grupos descontentes com os 12 anos de governo petista e com os escândalos envolvendo a Petrobras passaram a tomar as ruas se adensando e atraindo seguidores com outras pautas, incluindo algumas comportamentalmente autoritárias e economicamente neoliberais. O uso político-midiático da Operação Lava-Jato permitiu que grupos de interesse organizados primária e/ ou predominantemente por meio das redes sociais se associassem à grande imprensa, gerando manifestações massivas pelo Brasil, abrindo caminho para o impeachment de Rousseff e culminando na troca de governo em maio de 2016.

Esse contexto foi afeito ao fortalecimento dos movimentos de direita que apoiaram o impeachment, como Vem pra Rua e MBL, e as lideranças religiosas descontentes com os avanços no que se refere à igualdade de gênero e direitos sexuais. Discursos anti-institucionais foram se tornando mais poderosos, em especial por correntes que transformam adversários em inimigos por meio da oposição simplificadora entre "pessoas de bem" contra as supostas encarnações do "Mal". A retórica anticorrupção progressivamente foi sendo associada e/ou substituída por pautas moralistas/moralizantes no que se refere a gênero e sexualidade, que passaram a se fortalecer, como ocorre até os dias atuais. Um exemplo disso pode ser expresso pelo número de seguidores e compartilhamentos de posts de "empreendedores morais" - religiosos e agnósticos.

Em meados de 2018, as fanpages do deputado evangélico Feliciano e do então candidato a presidente Bolsonaro, contavam 4,5 e 5,5 milhões de seguidores respectivamente. Algumas de suas postagens alcançaram mais de Ioo mil compartilhamentos. Grupos como MBL e Vem pra Rua tinham no mesmo período 2,8 e dois milhões de seguidores, respectivamente. No entanto, no final de julho, o Facebook removeu I 96 fanpages e 87 perfis do MBL em combate às fake news abalando sua rede, o que talvez possa explicar o foco da campanha eleitoral de Bolsonaro no uso do aplicativo de mensagens Whatsapp e, como aponta investigação de um grupo de pesquisadores da Universidade de Harvard, na disseminação de vídeos no YouTube. ${ }^{\text {I3 }}$

Os dados compilados pelo Manchetômetro do Iesp/Uerj sobre os posts mais compartilhados e/ou curtidos das redes sociais permitem identificar uma 
ascensão dos empreendedores morais. Essa nova direita que se articula após 2013 evita discutir substancialmente temas como crescimento econômico, desemprego, meio ambiente, educação ou saúde. Em vez disso, seu foco está na disseminação do medo, recorrendo ao expediente de criação de pânicos morais - como os do fantasma da "ideologia de gênero"I4 ou de um possível retorno do "comunismo". Nesse sentido, as redes sociais têm tido papel fundamental na atuação de grupos conservadores que precisam angariar eleitores e apoio sem expor sua agenda econômica impopular que envolve reformas como da previdência, a redução de direitos trabalhistas e privatização de empresas públicas. O uso de fake news se explica pela necessidade desses grupos de interesse de manipular dados e informações assim como construir teorias e narrativas que permitam modelar a opinião pública a seu favor.

As redes sociais dão a falsa impressão de que a horizontalidade das interações equivaleria a um contexto mais democrático, mas diversos pesquisadores (Alcântara, 20I6; Merclé, 20I I; Miskolci \& Balieiro, 20I8) mostraram que redes são contextos desiguais e hierárquicos em que alguns exercem o papel de formadores de opinião, enquanto a maioria apenas repercute. Em uma rede como o Facebook, a maior parte dos usuários demonstra ser suscetível a formadores de opinião que reduzem disputas políticas a uma gramática moral, aproximando-as de uma concepção individualizada de mundo. Assim, grupos de interesse, líderes populistas e até celebridades ganham poder na vocalização de interpretações simplificadoras e polarizadas da realidade social.

O fenômeno aqui analisado mostra, entre vários aspectos, como ao contrário de diagnósticos repetidos nas últimas décadas, as TICs não tomaram o lugar tampouco tiraram o poder da mídia mainstream, aqui compreendida como a de massas, em especial a televisão e a impressa. Embora as redes sociais possam pautar a grande mídia, o que se observou foi a convergência delas com as mídias de massa como definidoras de disputas políticas e mobilizações. As TICs têm promovido, ao mesmo tempo, a individualização e o aumento da exposição aos conteúdos da mídia, o que - em termos históricos - reconhecemos como o capítulo mais recente iniciado com a passagem da tela grande do cinema para a da televisão até chegar aos smartphones.

Do entretenimento público passou-se ao doméstico e, deste, ao individual. De uma eventual visita ao cinema, passando pela audiência diária à TV, chegou-se à crescente exposição à mídia por meio dos smartphones, numa interação permanente via esse dispositivo (Miskolci \& Balieiro, 20I8: I48). Tal nível de exposição à mídia passa a moldar as ideias e a própria gramática relacional desenvolvida dentro e fora das redes sociais, o que explica a introdução - no vocabulário político - de noções como "protagonismo", que se baseia na lógica de popularidade online. Da mesma forma, a construção de heróis ou inimigos públicos revela a hegemonia de expedientes narrativos da imprensa sensacionalista. 
Em meio ao cenário de antipolítica - recusa dos partidos e dos políticos "tradicionais" e a suspeita com relação à democracia representativa -, grupos de interesse que se afirmam apartidários passam a pautar disputas (políticas) dentro de uma gramática moral afeita à construção, perseguição e destruição de supostos inimigos. Segundo Messenberg (2017: 637): "Os supostos inimigos podem ser desde organizações, partidos, ou grupos específicos: os comunistas, os negros, os gays, as feministas e todos aqueles que não partilham de seu universo mental". Ainda segundo a socióloga, a visão de mundo dos adeptos dessa corrente que segue grupos de interesse conservadores se caracteriza por defender causas anti-igualitárias e soluções autoritárias para temas polêmicos.

Em uma sociedade que tende a ser identificada com a opinião pública moldada pelas redes sociais, disputas entre grupos de interesses diversos tendem a ser interpretadas em termos de oposições binárias entre o bem e o mal, heróis e bandidos, certo ou errado. Instâncias mediadoras de conflito ou produtoras de análises críticas passam a ser também recusadas e até perseguidas, traduzidas por ataques a educadores, artistas e intelectuais (Balieiro, 20I8). A horizontalidade das redes online permite que amadores e diletantes - assim como grupos de interesse - ataquem o jornalismo ou a ciência, instâncias cujos discursos se assentam na averiguação de fatos e na construção de teorias baseadas em evidências. Trata-se de uma disputa em que os empreendedores das redes encontram uma janela de oportunidades para moldar a experiência da realidade dos outros usuários segundo seus interesses.

Como já mencionado, a disputa política nas mídias tende a um tipo de polarização estabelecido por uma gramática moral que divide os adversários em binários maniqueístas que facilmente passam de uma pauta macrossocial para o foco na moral ou ética de um grupo ou indivíduo. Assim, a disputa política online pode resvalar para a vigilância comportamental, como nos frequentes casos de denúncias que se confundem com o desejo não de justiça, mas de punição imediata e sem mediações. Fenômeno que se dá tanto na disputa entre grupos conservadores e progressistas quanto dentro deles, constituindo uma privatização da política no sentido de que as redes sociais favorecem uma agência política baseada na busca de soluções pessoais para problemas sistêmicos, tendência contemporânea mais ampla já reconhecida por diversos sociólogos, como apontam Hamlin e Peters (20I8), mas que Paton (20I4) mostra ser potencializada pelo caráter anti-institucional de redes criadas em plataformas online.

Grupos políticos tiram vantagem do ecossistema das plataformas para manipular notícias, estabelecer agendas e propagandear suas ideias, aumentando a desinformação e promovendo a polarização (Marwick \& Lewis, 20I7). Tais forças políticas são particularmente significativas na criação de conteúdos capazes de influenciar e persuadir eleitores indecisos e mal informados, exatamente as pessoas mais propensas a reverter os resultados das eleições (Pas- 
quale, 2006). Assim, as plataformas tecnológicas permitem que campanhas sejam deflagradas na forma histórica das antigas cruzadas morais potencializando ganhos políticos para grupos de interesse que se apresentam online como defensores da família ou das crianças, mas cujos objetivos são bem terrenos, como conquista de seguidores para pautas políticas e econômicas, vitórias eleitorais ou definição de políticas públicas (Miskolci \& Pereira, 20I9).

\section{CONCLUSÕES}

Conforme vimos no início do texto, os embates políticos entre setores de esquerda e direita envolvendo um certo nível de polarização, longe de ser uma característica recente ou produto dos serviços de redes sociais, já estava presente na internet desde a década de I990. Ainda que não se possa atribuir responsabilidade exclusiva às redes sociais - ou ao Facebook em particular -, sua forma de funcionamento catalisa e aprofunda conflitos já existentes. Seguindo a linha sociológica da moldagem social da tecnologia, atribuir às TICs a criação dos conflitos e oposições constituiria determinismo tecnológico só sendo possível reconhecer que - segundo os dados empíricos - elas apenas os visibilizam, amplificam e radicalizam - entre outras razões, porque as redes sociais propiciaram a revelação da diferença, de ideologias, de opiniões e pensamentos antes não expressos publicamente e que, agora reconhecidos, geram substratos para conflitos. ${ }^{15}$

O fato acima é indissociável da consolidação do oligopólio de empresas do Vale do Silício que mantém a hegemonia do ecossistema de plataformas de rede social do presente. Antes que a internet se concentrasse nas mãos de poucas empresas, era comum que as pessoas usassem um grande número de sites, tivessem vários perfis específicos e usassem, portanto, a rede para se comunicar de diferentes formas com diferentes públicos. Eram essas as diferentes identidades/perfis que se possuía na rede, que não se comunicavam entre si e que praticamente tinham vida própria, proporcionando uma situação que dificultava monitoramento e vigilância comportamental. Existiam "silos de informação" que não se comunicavam, dando uma sensação de relativo anonimato e permitindo uma segmentação das interações menos propensa a conflitos.

O controle econômico da rede, por empresas como o Facebook e o Google, gerou o profiling de cada indivíduo que se conecta à rede, consequentemente uma crescente unificação dos perfis que equilibravam uma gama variada e diversa de relacionamentos. Os diferentes contextos de relacionamentos, nos quais negociávamos nossa identidade e nos ajustávamos de alguma forma ao interlocutor, acabou se colapsando. Soma-se isso ao fato de se tratar de uma comunicação rápida e individual que gera registros contínuos, levando a um risco alto de incompreensões e produção de divergências. Assim, colapsam também as formas de mediação predominantes no off-line ou na época dos perfis segmentados e, entre elas, as convenções que demandavam empatia 
e/ou respeito à alteridade, liberando comportamentos e opiniões negativos e até agressivos em relação àqueles dos quais se diverge.

O modo de funcionamento do Facebook gera bolhas de opinião em torno de certos consensos, os quais, por sua vez, se consolidam por meio de oposições a outras "bolhas"/grupos sociais. O colapso contextual tende a expor diferenças, gerar atritos, incentivar respostas indignadas, apoios apaixonados ou mesmo rechaços baseados na projeção de preconceitos. Numa escala mais ampla e repetida ao longo do tempo, essa dinâmica rompe pactos sociais silenciosos de tolerância, destrói as formas de mediações preexistentes e coloca temas complexos num debate raso e simplificador em que todos são juízes ou réus do pensamento alheio. Ao mesmo tempo, as redes digitais expõem maniqueísmos já presentes na sociedade, permitindo transformá-los em objeto de análise científica.

Neste artigo, buscamos contribuir para uma reflexão necessária sobre o papel das redes sociais na inflexão política que vivemos, no Brasil e no resto do mundo, a partir de 20I3. Segundo as fontes históricas consultadas é possível não apenas reconhecer esse ponto de inflexão, mas também associá-lo a uma convergência entre momento histórico e maior socialização por meio de plataformas. O extremismo conflitivo desse novo ambiente tem sido mais bem explorado por vertentes políticas conservadoras já que o cenário global, desde a crise de 2008 , criou temores sobre o futuro. Assim, idealizam-se passados supostamente melhores, mais estáveis e prósperos. Esse medo do futuro alimenta lideranças populistas em uma gramática política que cria bodes expiatórios em cada contexto nacional. Assim se vê, por exemplo, no slogan vitorioso de Donald Trump do "Make America Great Again" e sua retórica anti-imigrantes.

O papel das redes sociais nesse contexto tem sido central tanto por suas características tecnológicas - como a indução algorítmica de interações - quanto pela maneira como também elas induzem seus usuários a incorporar modelos midiático-comerciais na construção de seus perfis e, a partir deles, de sua agência online e off-line. Acessadas individualmente, as redes apresentam ao usuário uma visão "customizada" e parcial da realidade, incentivando leituras individualistas de questões sistêmicas ou estruturais, além de expô-lo a narrativas e interpretações criadas e disseminadas de forma organizada por grupos políticos que fazem uso de expedientes de manipulação para alcançar seus objetivos.

Nas redes sociais, quanto mais simples e baseadas em valores arraigados as pautas tendem a angariar mais apoio, criando redes de mobilização política assentadas em uma espécie de empreendedorismo moral. No Brasil, as mencionadas características tecnológicas e midiáticas abriram uma janela de oportunidades nas redes sociais para a criação de uma aliança circunstancial de grupos de interesse em torno de uma plataforma moral, que abarca desde a luta contra a corrupção, uma suposta ameaça comunista até o fantasma da 
"ideologia de gênero". Os candidatos da extrema-direita eleitos em 2018 comportaram-se como empreendedores morais evitando discutir temas substantivos como educação, saúde e desemprego. Além da agenda conservadora e autoritária nos costumes, a maioria compartilha um projeto econômico neoliberal que dificilmente teria tido o mesmo apoio se tivesse sido apresentado como plataforma eleitoral.

Uma pauta conservadora com origens em setores religiosos tornou-se predominantemente agnóstica a partir do momento que passou a se centrar no referente "ideologia de gênero", expressão afeita à associação simplista e enganosa entre esquerda e feminismo, criando um inimigo comum para uma verdadeira aliança entre grupos de interesse com histórias e objetivos tão diversos como o MBL e o Escola sem Partido. Desde então, têm-se associado oportunisticamente a empreendedores morais históricos como a Igreja católica e vertentes evangélicas neopentecostais em campanhas contra educadores, artistas e intelectuais (Miguel, 20I6). Tais forças revelaram-se bem-sucedidas ao impedir a introdução de uma perspectiva de gênero nos planos educacionais ou medidas contra a discriminação sexual nas escolas, mas sobretudo por angariar apoio eleitoral para a extrema-direita, culminando na eleição de Jair Bolsonaro para presidente - aquele que iniciou a cruzada moral ao criar uma campanha contra o material educacional anti-homofobia nominado por ele kit gay, em 20I I, e, em 20I6, dedicou seu voto pelo impeachment de Dilma Rousseff, nossa primeira presidente mulher, ao seu torturador.

As fontes históricas e sociológicas provam que as redes sociais, em especial o Facebook, foram decisivas para que as Jornadas de Junho de 2013 tenham constituído um ponto de inflexão na vida brasileira, um ponto que modificou as relações políticas tornando-as não apenas mais polarizadas e conflitivas, mas também moldadas por uma gramática moral e anti-institucional. A formação de redes polarizadas induzidas pela mídia alcançou seu extremo mais conhecido na era dos smartphones, da conexão perpétua e da sociabilidade por plataformas comerciais produzindo "bolhas" na mesma proporção em que gera perseguição e ataques a quem não se identifica completamente com essas redes. De forma menos visível - e talvez até mais poderosa - esse contexto passou a definir os contornos de nossa visão de mundo e de nossa ação política. 
Jorge Machado é professor-associado da Escola de Artes, Ciências e Humanidades da Universidade de São Paulo. É um dos coordenadores do Co-Laboratório de Desenvolvimento e Participação. Foi professor convidado da Zeppelin Universität, Alemanha (2017). Atua na área de políticas públicas, dedicando-se principalmente aos seguintes temas: políticas de informação, políticas acesso ao conhecimento, participação política e temáticas associadas à tecnologia de informação e direitos. Publicou recentemente o artigo "Infraestruturas, economia e política informacional", em que discute com outros autores as consequências do controle das infraestruturas de informação

globais por corporações.

Richard Miskolci é professor-associado de sociologia da Unifesp, pesquisador do CNPq e coordenador do Quereres - Núcleo de Pesquisa em Diferenças, Direitos Humanos e Saúde. Foi coordenador adjunto da área de sociologia na Capes entre $2015 \mathrm{e}$ 20I8. Doutor em sociologia pela USP, fez estágios sêniores em departamentos de estudos feministas da Universidade de Michigan e da Universidade da Califórnia. Tem desenvolvido investigações na sociologia digital, área em que organizou dossiê, publicou diversos artigos e o livro Desejos digitais: uma análise sociológica da busca por parceiros online (2017). 


\section{NOTAS}

I O Manchetômetro é um website de acompanhamento da cobertura das grandes mídias e das redes sociais sobre temas de política e economia produzido pelo Laboratório de Estudos de Mídia e Esfera Pública (Lemep) do Iesp/Uerj. Disponível em <www.manchetometro.com.br>. Acesso em I9 ago. 2018.

2 O escândalo envolvendo a Cambridge Analytica na eleição dos Estados Unidos mostra o uso da rede para manipulação da opinião pública com fins políticos a partir da análise de dados comportamentais e de valores dos usuários e, com isso, o emprego de micro-targeting. A atuação da Cambridge foi exitosa por se concentrar nos estados norte-americanos em que havia pouca vantagem dos democratas, atingindo grupos de leitores específicos com propensão à mudança de votos na abordagem de temas sensíveis, como direito ao aborto e porte de armas.

3 Apple, Google, Microsoft, Facebook e Amazon passaram a ocupar, em 20I7, as cinco primeiras posições no ranking das companhias mais valiosas do mundo, deixando para trás gigantescas corporações globais, que durante décadas tinham posições de liderança como Exxon, Nestlé, Samsung, General Electric e Johnson \& Johnson. Em pouco mais de dez anos, empresas que praticamente não produzem bens físicos e que têm o big data como um de seus principais ativos, "tornaram-se as maiores da história do capitalismo global, superando as corporações multinacionais da indústria automobilística, petrolífera e de alimentos. Essas mesmas empresas - com exceção da Amazon - se tornaram atores fundamentais para o programa de vigilância PRISM, conforme os vazamentos de Edward Snowden" (Parra et al., 20I8: 66).

4 "Nova ordem mundial" foi a expressão empregada por George H. W. Bush (I989-I993) para definir a governança global depois da Guerra Fria, com a liderança mundial centralizada nos Estados Unidos da América a partir da Guerra do Golfo (I990-I99I).

5 O primeiro smartphone foi o iPhone da Apple, lançado em 2007. Em 2008, são lançados os sistemas operacionais iOS e Android e, a partir de 2009, são criadas as condições para o acesso celular à internet por meio de conexão mais rápida, geolocalização e o desenvolvimento de aplicativos por ter- 
ceiros. Dados de acesso global - e também regional ou por país - podem ser acessados no website da ITU e seus relatórios, disponível em <https://www.itu.int/en/Pages/default. aspx>. Acesso em i9 ago. 2018.

6 Pesquisa Nacional de Amostragem por Domicílio (IBGE, 20I4) - Acesso à internet e à televisão e posse de telefone móvel celular para uso pessoal. Disponível em <http://biblioteca.ibge.gov.br/visualizacao/livros/liv95753.pdf >. Acesso em I9 ago. 2018.

7 Aqueles que acessaram a internet comercial desde seu lançamento em meados da década de I990, tinham a impressão de acessar o mundo, ainda que - efetivamente - o mais provável é que os sites disponíveis refletiam os interesses e proviam conteúdos de segmentos sociais privilegiados em termos culturais e econômicos. O acesso era caro, assim como os equipamentos. Além disso, os sites visitados não eram vistos como "bolhas" porque ainda não era possível perceber as segmentações existentes de forma tão clara como atualmente percebemos dentro de uma mesma plataforma de rede social.

8 "Logar" é um neologismo que se refere ao ato de acessar sites online por meio de um nome de usuário e senha, os quais têm convergido para uma identidade digital única de cada indivíduo. O usuário voluntariamente tende a usar o mesmo email/nome de usuário e senha para navegar entre diferentes portais e sítios devido à praticidade que isso confere à navegação e supostos benefícios como o de uma "navegação personalizada" e a integração de suas "preferências" nas visualizações.

9 Embora existam ferramentas no Facebook para segmentação do público a quem se publica, elas ainda são pouco utilizadas pelos usuários, prevalecendo na plataforma como uma comunicação com todos praticamente ao mesmo tempo.

Io Fake news são notícias falsas disseminadas online visando promover boatos, má-informação e/ou desinformação. As fake news podem emergir a partir de interesses, desejos e perspectivas de indivíduos, empresas ou grupos políticos. Elas podem ser convincentes a ponto de ser aceitas como verdade, gerando efeitos sociais e políticos. Atualmente, grupos de interesse defendem as fake news por meio da tese 
de chegada de uma "política da pós-verdade" ou "política do pós-fato", termos que servem para justificar ataques a instituições como a imprensa e a ciência no intuito de distorcer fatos e evidências para conquistar apoio de segmentos sociais.

I I Para uma análise das Jornadas de Junho como expressão contemporânea do fenômeno histórico da ação direta, consulte Barreira, 20I4.

I2 Disponível em <https://wwwi.folha.uol.com.br/cotidiano /2013/06/I 298903-mpl-suspende-novas-manifestacoesem-sao-paulo.shtml>. Acesso em I9 ago. 2018.

I3 O jornal Folha de S. Paulo denunciou, no início de 2019, um suposto esquema de financiamento de disparo de mensagens no Whatsapp que teria favorecido a campanha de Bolsonaro e aliados nas eleições de 20I8. No segundo semestre de 20I9, Jonas Kaiser e Yasodara Córdova, pesquisadores do Berkman Klein Center for Internet and Society da Universidade de Harvard, divulgaram dados que apontam que o algoritmo do YouTube no Brasil teria contribuído para a expansão da extrema-direita (cf. Fisher \& Taub, 20I9).

I4 "Ideologia de gênero" é expressão criada na década de I99o por intelectuais e ativistas (religiosos e laicos) que se opõem aos estudos de gênero e às demandas políticas dos movimentos feministas e LGBT como a igualdade entre homens e mulheres, casamento entre pessoas do mesmo sexo, acesso às tecnologias reprodutivas, contracepção e interrupção da gravidez, educação sexual e criminalização da homofobia. Para uma genealogia completa do termo e da formação de um movimento contra os direitos sexuais e reprodutivos, ver Miskolci 2018.

I5 Agradecemos a um dos pareceristas por nos auxiliar a chegar a essa constatação.

\section{REFERÊNCIAS BIBLIOGRÁFICAS}

Alcântara, Lívia M. de. (20I6). Ciberativismo e a dimensão comunicativa dos movimentos sociais: repertórios, organização e difusão. Política e Sociedade, I5/34, p. 315-338.

Balieiro, Fernando de Figueiredo. (2018). 'Não se meta com meus filhos': a construção do pânico moral da criança sob ameaça. Cadernos Pagu, 53. Disponível em <http://www. 
scielo.br/scielo.php?script=sci_arttext\&pid=SoI04$83332018000200406 \& \operatorname{lng}=\mathrm{pt} \& \mathrm{nrm}=\mathrm{iso} \& \mathrm{t} \operatorname{lng}=\mathrm{pt}>$. Acesso em I9 ago. 2018.

Barreira, Irlys. (20I4). Ação direta e simbologia das "jornadas de junho": notas para uma sociologia das manifestações. Contemporânea - Revista de Sociologia da UFSCar, 4/I, p. I45-I64.

Boutang, Yann M. (2005). Riqueza, propiedad, libertad y renta en el capitalismo cognitivo. In: E. Rodríguez, E. \& Sánchez, R. (org.). Capitalismo cognitivo, propiedad intelectual y creación colectiva. Madrid: Traficantes de Sueños. Disponível em <http://e-tcs.org/wp-content/uploads/2012/Io/E-Boutang Riqueza_Propiedad_y_renta.pdf>. Acesso em I9 abr. 2018.

Burrows, Roger \& Beer, David. (2013). Rethinking space: urban informatics and the sociological imagination. In: Orton-Johnson, K. \& Prior, N. Digital sociology. London: Palgrave MacMillan, e-book.

Davenport, Thomas H. \& Beck, J. C. (200I). The attention economy: understanding the new currency of business. Boston: Harvard School of Business. Disponível em <https://books.google.com.br/books?hl=de\&lr=\&id=FuuKd3ongpsC \&oi=fnd \& pg=PRI $2 \& d q=\%$ 22economy+of+attention \% 22+internet\&ot $\mathrm{s}=\mathrm{RLYRKv} \_03 \mathrm{x} \& \mathrm{sig}=\mathrm{LcHmnXcdjbGMFUBvH4gMkB2e5OY \&}$ redir_esc $=\mathrm{y} \# \mathrm{v}=$ onepage $\& \mathrm{q}=\%$ 22economy $\% 200 \mathrm{f} \%$ 20atten tion\%22\%2ointernet\&f $\mathrm{f}$ false $>$. Acesso em I9 abr. 2018.

Fisher, Max \& Taub, Amanda. (2019). How YouTube radicalized Brazil. The New York Times. Disponível em <https://www. nytimes.com/20I9/08/II/world/americas/youtube-brazil. html>. Acesso em I9 ago. 2018.

Foster, John Bellamy \& McChesney, Robert. (20I4). Surveillance capitalism: monopoly-finance capital, the militaryindustrial complex, and the digital age. Monthly Review, 66/3. Disponível em <https://monthlyreview.org/20I4/o7/or/ surveillance-capitalism/>. Acesso em I9 abr. 2018.

Gillespie, Tarleton. (2013). The relevance of algorithms. In: Gillespie, Tarleton; Boczkowski, Pablo \& Foot, Kirsten (eds.). Media Technologies, p. I67-I94. Cambridge, MA: MIT Press.

Goldhaber, Michael H. (I997). The attention economy and the Net. First Monday, 2, p. 4-7. Disponível em <http://journals.uic.edu/ojs/index.php/fm/article/view/5I9>. Acesso em I9 abr. 2018. 
Hamlin, Cynthia \& Peters, Gabriel. (2018). Consumindo como uma garota: subjetivação e empoderamento na publicidade voltada para mulheres. Lua Nova, 103, p. 167-202.

Hardt, Michael \& Negri, Antonio. (2004). Multidão: guerra e democracia na era do Império. Tradução de Berilo Vargas. Rio de Janeiro: Record.

Introna, Lucas D. \& Nissenbaum, Helen. (2000). Shaping the web: why the politics of search engines matters. The Information Society, I6/3, p. I69-185.

Machado, Jorge Alberto S. (2007). Ativismo em rede e conexões identitárias: novas perspectivas para os movimentos sociais. Sociologias, I8, p. 248-285. Disponível em <https:// dx.doi.org/IO.I590/Si517-452220070002000I2>. Acesso em I9 ago. 2018.

Marwick, Alice E. \& Boyd, Danah. (2010). I tweet honestly, I tweet passionately: twitter users, context collapse, and the imagined audience. New Media \& Society, I3/I, p. II4-I33. Disponível em <https://doi.org/Io.II77/I46I4448I03653I3>. Acesso em I9 ago. 2018.

Marwick, Alice E. \& Lewis, Rebecca. (2017). Media manipulation and disinformation online. Data \& Society Research Institute. Disponível em <https://datasociety.net/pubs/oh/ DataAndSociety_MediaManipulationAndDisinformationOnline.pdf >. Acesso em I9 abr. 2018.

Merclé, Pierre. (20I I). Sociologie des reseaux sociaux. Paris: La Découverte.

Messemberg, Debora. (2017). A direita que saiu do armário. Sociedade e Estado, 32/3, p. 62I-647. Disponível em <http:// www.scielo.br/scielo.php?script=sci_arttext\&pid=SoIO2 6992201700030062 I \&lng $=$ en $\& \mathrm{nrm}=\mathrm{iso} \& \mathrm{t} \operatorname{lng}=\mathrm{pt}>$. Acesso em I9 abr. 2018.

Miguel, Luis Filipe. (20I6). Da “doutrinação marxista” à "ideologia de gênero" - Escola sem Partido e as leis da mordaça no parlamento brasileiro. Direito \& Práxis, 7/I5, p. 590-56I. Disponível em <http://www.e-publicacoes.uerj.br/index.php/revistaceaju/article/view/25I63>. Acesso em I9 abr. 2018.

Miskolci, Richard. (20I8). Exorcisando um fantasma: os interesses por trás do combate à "ideologia de gênero". Cadernos Pagu, 53, epub. Disponível em <http://www.scielo.br/ scielo.php?script=sci_arttext \&pid=SoI04-833320I800 0200402 \&lng=pt\&tlng=pt $>$. Acesso em I9 abr. 2018. 
Miskolci, Richard \& Balieiro, Fernando de Figueiredo. (2018). Sociologia digital: balanço provisório e desafios. Revista Brasileira de Sociologia, 6/I2, p. I32-I56. Disponível em <http:// www.sbsociologia.com.br/revista/index.php/RBS/article/ view/237>. Acesso em I9 ago. 2018.

Miskolci, Richard \& Pereira, Pedro Paulo Gomes. (2019). Educação e saúde em disputa: movimentos anti-igualitários e políticas públicas. Interface: Comunicação, Saúde, Educação, 23 , epub. Disponível em <http://www.scielo.br/scielo. php? script=sci_arttext $\&$ pid $=$ S I 4 I 4-328320 I 9000 I 00 $400 \& \operatorname{lng}=\mathrm{pt}>$. Acesso em I4 ago. 2019.

O'Reilly, Tim. (2013). Open data and algorithmic regulation. In: Goldstein, Brett (ed.). Beyond transparency: open data and the future of civic innovation. San Francisco: Code for America Press, p. 289-300.

Ortiz, Pedro H. F. (2005). Das montanhas mexicanas ao ciberespaço. Estudos Avançados, I9/55, p. I73-I86. Disponível em: <https://dx.doi.org/IO.I590/SoI03-40I420050003000I 2>. Acesso em i9 abr. 2018.

Pariser, Eli. (20II). The filter bubble: what the internet is hiding from you. London: Penguin Books.

Parra, Henrique et al. (20I8). Infraestruturas, economia e política informacional: o caso do Google Apps For Education. Mediações - Revista de Ciências Sociais, 23/I, p. 63-99.

Pasquale, Frank. (20I7) A esfera pública automatizada. Líbero, 39. Disponível em: <http://seer.casperlibero.edu.br/index. php/libero/article/view/866/832>. Acesso em I9 abr. 2018.

Pasquale, Frank. (2006). Rankings, reductionism, and responsibility. Cleveland State Law Rev, 54, p. II5-I39. Disponível em <https://digitalcommons.law.umaryland.edu/cgi/view content.cgi article $=2355 \&$ context $=$ fac_pubs $>$. Acesso em I9 abr. 2018.

Paton, Nathalie. (20I4). School shooting: la violence à l'ère de YouTube. Paris: Éditions de la Maison des sciences de l'homme.

Patschiki, Lucas. (2012). Os litores da nossa burguesia: o Mídia sem Máscara em atuação partidária (2002-20I I). Dissertação de Mestrado (História). Universidade Estadual do Oeste do Paraná. 
Pickard, Victor. (2006). United yet autonomous: indymedia and the struggle to sustain a radical democratic Network. Media, Culture \& Society, 28/3, p. 3I5-336. Disponível em $<$ https://do i.org/ıo.II77/or6344370606I685>. Acesso em i9 abr. 2018

Pomar, Marcelo. (2013). Não foi um raio em céu azul. In: Judensnaider, E.; Lima, L. \& Ortellado, P. (orgs.). Vinte centavos: a luta contra o aumento. São Paulo: Editora Veneta.

Ramos, Jair. (20I5). Subjetivação e poder no ciberespaço: da experimentação à convergência identitária na era das redes sociais. Vivência, 45, p. 57-76. Disponível em <https://periodicos.ufrn.br/vivencia/article/view/825I >. Acesso em I9 abr. 2018.

Rouvroy, Antoinette \& Berns, Thomas. (20I5). Governamentalidade algorítmica e perspectivas de emancipação: o díspar como condição de individuação pela relação? Revista ECO-Pós, I8/2, p. 36-56. Disponível em <https://revistas.ufrj. br/index.php/eco_pos/article/view/2662>. Acesso em I9 abr. 2018.

Thrift, Nigel. (2004). Remembering the technological unconscious by foregrounding the knowledges of position. Environment \& Planning: society and space, 22/I, p. I75-I90.

Turkle, Sherry. (20II). Alone together: why do we expect more from technology and less from each other? New York: Basic Books.

Van Dijck, Jose. (20I6). La cultura de la conectividade. Buenos Aires: Siglo Veinteuno.

Williams, Raymond. (20I5). Televisão: tecnologia e forma cultural. São Paulo: Boitempo.

Zuboff, Shoshana. (2016). The secrets of surveillance capitalism. Frankfurter Allgemeine Zeitung, caderno Feuilleton. Disponível em <http://www.faz.net/aktuell/feuilleton/debatten/the-digital-debate/shoshana-zuboff-secrets-ofsurveillance-capitalism-I4I036I6.html? printPagedArticle =true\#pageIndex_2>. Acesso em I9 abr. 2018.

Zuboff, Shoshana. (2015). Big other: surveillance capitalism and the prospects of an information civilization. Jounal of Information Technology, 30, p. 75-89. Disponível em <https:// cryptome.org/2015/07/big-other.pdf>. Acesso em ig abr. 2018. 


\section{DAS JORNADAS DE JUNHO À CRUZADA MORAL: \\ O PAPEL DAS REDES SOCIAIS NA POLARIZAÇÃO POLÍTICA BRASILEIRA}

Resumo

O objetivo deste texto é compreender o papel desempenhado pelas redes sociais na polarização política. Na perspectiva da moldagem social da tecnologia, desenvolve uma análise sociológica e histórica das características da sociabilidade por meio de plataformas num contexto de uso individualizado de dispositivos de conexão. Os protestos de 2013 são tomados como ponto de inflexão a partir do qual disputas políticas passaram a se dar por meio de uma gramática moral. O artigo analisa como a concentração do uso da internet em poucas plataformas afetou as comunicações que antes eram mediadas pelas pessoas em diferentes contextos, unificando-as de forma a acentuar oposições binárias e a formação de consensos polarizados.

\section{FROM THE JUNE DEMONSTRATIONS TO THE MORAL} CRUSADE: THE ROLE OF SOCIAL MEDIA NETWORKS IN POLITICAL POLARIZATION

\begin{abstract}
vices. The 2013 demonstrations are taken as the turning point after which political disputes began to unfold through a moral grammar. The article analyses how the concentration of internet use on a few platforms has altered communications previously mediated between people in different contexts, unifying them in a way that accentuates binary oppositions and the shaping of polarized consensuses.
\end{abstract}

Palavras-chave

Jornadas de Junho; polarização política; internet; redes sociais e disputas morais.

\section{Keywords}

Demonstrations of June; political polarization; internet; digital social networks and moral disputes. 